\title{
Access to and Experiences of Higher Education Across Europe: The Impact of Social Characteristics
}

\author{
Rachel Brooks, Jessie Abrahams, Predrag Lažetić, Achala Gupta, \\ and Sazana Jayadeva
}

\section{Introduction}

Policymakers across Europe have increasingly emphasised the importance of paying close attention to the social dimension of higher education and taking further steps to ensure that the composition of Europe's universities more adequately reflects the diversity of the wider population. While there have been a number of studies that have explored this through analyses of European- and national-level policy and others that have assessed a range of quantitative indicators related to student diversity, this chapter assumes, in contrast, an interpretivist stance; it is interested in the perspectives of those studying and working 'on the ground' within the European Higher Education Area. Specifically, we seek to answer this research question: To what extent do students and staff, across Europe, believe that higher education access and experiences are differentiated by social characteristics (such as class/family background, race/ethnicity/migration background, gender and age)? In doing so, we draw on data from a large European Research Council-funded project, including 54 focus

R. Brooks ( $)$

University of Surrey, Surrey, UK

e-mail: r.brooks@surrey.ac.uk

A. Gupta $\cdot$ S. Jayadeva

University College London, London, UK

e-mail: achala.gupta@ucl.ac.uk

S. Jayadeva

e-mail: s.jayadeva@ucl.ac.uk

J. Abrahams

University of Bristol, Bristol, UK

e-mail: jessie.abrahams@ bristol.ac.uk

P. Lažetić

University of Bath, Bath, UK

e-mail: p.lazetic@bath.ac.uk

(C) The Author(s) 2020

A. Curaj et al. (eds.), European Higher Education Area: Challenges for a New Decade, https://doi.org/10.1007/978-3-030-56316-5_14 
groups with undergraduate students (a total of 295 individuals) and 72 in-depth individual interviews with members of higher education staff (both academic and non-academic). Fieldwork was conducted in three higher education institutions in each of the following countries: Denmark, UK-England, ${ }^{1}$ Germany, Ireland, Poland and Spain - nations chosen to provide diversity with respect to welfare regime, relationship to the European Union (EU) and mechanisms for funding higher education. We explore commonalities and differences between staff and students and between different countries, before identifying some implications for policymakers keen to promote further social inclusion within Europe's higher education institutions (HEIs).

\section{Background}

Education is often seen, by various commentators, as an important space for social mixing, where people from a variety of different backgrounds can come together and learn from one another. Indeed, Bennett et al. (2017) have argued that, within relatively large educational institutions, 'the formal processes of learning, delivering the certificates, is accompanied by more informal processes in which students manage and negotiate difference .... Colleges are key sites within which urban multiculture is experienced and through which it is defined' (p. 2319). Nevertheless, studies from across the world have documented how, with respect to higher education, despite processes of massification, student bodies often remain far from diverse, with those from 'non-traditional' backgrounds under-represented and, in many cases, more likely to drop-out during their studies or attain a lower level of qualification than their more privileged peers (e.g. Bathmaker et al. 2016; Bunn et al. 2019).

Within Europe, there have, over the past 20 years or so, been significant efforts to widen access to higher education for traditionally under-represented groups and to ensure that they succeed during their degree programmes. For example, within the Bologna Process, a 'social dimension' was included to encourage all signatory states to adopt measures to improve the inclusivity of their higher education sector, with the stated aim of ensuring that the student body within Europe represented 'the diversity of our populations'. The 2015 Yerevan Communiqué reiterated this commitment: social inclusion was specified as one of four priority policy areas. Nevertheless, despite these pronouncements, progress has been slow and variable (Pérez Cañado 2015). Indeed, the executive summary to The European Higher Education Area in 2018 report noted:

Social dimension challenges have accompanied the Bologna Process throughout its existence. Yet, disadvantaged learners still face access barriers to higher education: students from low and medium- educated families are strongly under-represented, and are more likely to enter higher education with a delay; gender imbalances, if improving slightly, still persist and remain marked in some discipline areas with significant implications for the labour market and society; and life-long learning is not a reality for learners in many countries.

\footnotetext{
${ }^{1}$ England rather than the whole of the UK was chosen because of the significant differences between the higher education systems in the four nations of the UK. In this chapter, we refer to England as 'UK-England'.
} 
In addition to barriers to access, disadvantaged students also face difficulties in completing higher education, dropping out in higher proportions. Despite evidence of these trends over a number of years, and commitments re-iterated in several ministerial communiqués, only a few countries have introduced measures in recent years to improve the conditions for under-represented groups to access and complete higher education. (European Commission/EACEA/Eurydice 2018a, p. 15)

Where progress has occurred, it has often been within higher education institutions perceived as of lower prestige and/or which occupy relatively low positions in league tables (Boliver 2013; Pérez Cañado 2015). In explaining this relative lack of progress, some scholars have pointed to the policy measures used by the European Union. Weedon and Riddell (2015) claim, for example, that relying on relatively 'soft' forms of governance, such as the Open Method of Co-ordination (which has operated independently of the Bologna Process), has been insufficient to motivate change on the part of national governments. Countries have only been 'invited' to adopt national objectives to promote social inclusion, and commitments in this area have not been legally binding. (Indeed, it is currently not possible for any such commitments to be legally binding either under the Bologna Process or through the European Union policy in higher education.) This has resulted in countries choosing to focus on different groups of under-represented students and not always monitoring the success of implemented measures. In 2014, Eurydice reported that most European countries claimed that they did not have sufficient data to say whether the diversity of their national student body had changed (Eurydice 2014). Even by 2018, relatively few countries had adopted quantitative targets for improving the participation or attainment of under-represented groups (European Commission/EACEA/Eurydice 2018b). (Of the six countries in our study, only Ireland and UK-England had adopted such targets.) Furthermore, only three nations (France, UK-England and UK-Wales) had adopted all of the five indicators relating to student diversity that had been suggested by the European Commission (ibid.).

Scholars have also maintained that there has been a long-standing tension between the social and economic goals of the Bologna Process, with Robertson (2009), for example, suggesting that its various social objectives have served primarily as a smokescreen to conceal the economic drivers that underpin the initiative. This tension has led to a lack of clarity, within policy, about the priority that should be given to measures to promote social inclusion and the specific groups upon whom measures should be targeted (Weedon and Riddell 2015). Moreover, targets set at the European level have typically excluded measures of social inclusion. The EU's Education and Training Strategy 2020 (which is distinct from the Bologna Process), for example, specifies that, by $2020,40 \%$ of 30-34 year olds in the EU should have completed higher education, but there is no particular focus on the participation of under-represented groups ${ }^{2}$ (ibid.). Studies conducted within specific nation-states have indicated that, often, there is considerable ambiguity and lack of clarity associated with policies in this area. Writing with respect to Germany, Klein (2016) has

\footnotetext{
${ }^{2}$ To some extent, the lack of focus on under-represented groups is associated with some of the points made later in the chapter, namely differences in understandings related to this area across Europe, and the relative lack of data at the national level in many countries.
} 
argued that while some measures have been introduced to increase the heterogeneity of the student body and strengthen the competence of staff to work with a more diverse student body, these have suffered from the absence of any overall strategy or coherent concept of diversity-with economic and social justice rationales often in tension. She also contends that lack of agreement about what categories diversity initiatives should cover impeded work in this area, and were often exploited by those who wanted to undermine the idea of equity altogether.

In many respects, the European experiences, outlined above, are reflected in other parts of the world. The challenges of promoting 'diversity' in higher education institutions have been noted by several scholars. They have shown how initiatives can often be about promoting recognition and tolerance rather than structural change (Deem and Morley 2006), and have more in common with marketing efforts than transformation. Indeed, Ahmed (2007) has argued, with respect to ethnicity in particular, 'Not only does this re-branding of the university as being diverse work to conceal racism, but it also works to re-imagine the university as being anti-racist and even beyond race' (p. 606). Appearances are thus altered, but not the university cultures that underpin them. Research has also indicated that, as within Europe, progress towards widening participation and securing the educational success of traditionally under-represented students tends to be best in lower status institutions (i.e. those perceived as less prestigious and/or which are ranked relatively lowly in league tables) (Marginson 2016).

The research reported in this chapter takes this policy context as a point of departure and explores the extent to which considerations of social characteristics inform higher education staff and undergraduates' understandings of the contemporary student.

\section{Methods}

We draw on data collected as part of a European Research Council-funded project ('Eurostudents'), which considers the ways in which higher education students are conceptualised in six European countries: Denmark, UK-England, Germany, Ireland, Poland and Spain. These countries were chosen so as to provide some diversity with respect to welfare regime; relationship to the European Union; mechanisms for funding higher education; and available sources of student support (such as grants and loans). Between 2017 and 2019, in each country, we conducted fieldwork in three higher education institutions, selected to represent key dimensions of the higher education sector in that country. In Ireland, for example, we included an institute of technology in our sample, as well as two universities. In each higher education institution, we conducted three focus groups with undergraduate students from a wide range of subject areas and individual interviews with at least four members of staff. Where possible, we included both academic and non-academic employees in our sample. In total, our sample comprised 295 students and 72 members of staff. All the staff interviews were conducted in English. The student focus groups were conducted 
in English in UK-England, Denmark and Ireland; in the other three countries, they were carried out in the native language and then translated prior to analysis. All interviews were audio-recorded, fully transcribed and analysed (employing both inductive and deductive approaches) using NVivo.

During the interviews and focus groups, we were keen to explore the ways in which our respondents understood what it means to be a higher education student in their country today, and we asked them a variety of open-ended questions about this. The undergraduate students were also asked to make plasticine models of how they thought about themselves, as students, and how they thought they were seen by others. We then asked both groups of respondents (staff and students) a more specific question about whether they believed these understandings differed by the social characteristics of the students, such as social class/family background, gender, ethnicity and migration background. It is the responses to this particular question that inform this chapter. In the sections below, we outline the views of both staff and students, before discussing them together in the final section.

\section{Staff Perspectives}

Many of our staff interviewees believed that what it means to be a contemporary higher education student is, to some extent at least, differentiated by social characteristic. However, unlike the student sample (discussed below), they each tended to focus on a small number of factors, and often just one. Moreover, as might perhaps be expected in light of the discussion above, in which variability across Europe-at the level of policy_-was emphasised, the narratives of the staff we interviewed mapped on quite closely to national priorities and discourses, with clear contrasts evident between countries. In Germany, for example, there was much more concern about the ways in which immigrants may be disadvantaged within universities than in the other five countries. Staff in German HEI $1,{ }^{3}$ for example, reflected on the struggles they had encountered in trying to support those who had recently immigrated to Germany:

Those who come from more recent immigrant waves, that's a sort of harder thing to figure out how to support them. It could be anything from the writing and dealing with the language issues to [coping with an unfriendly local non-student population, many of whom are opposed to Germany's position on migration]

As we have argued elsewhere (Brooks 2018a, 2019), Germany's higher education policies more generally take a markedly different position from the other five countries in our sample on inward migration, arguing that the sector has a particular responsibility for integrating refugees, for example. This is closely related to Germany's broader migration policy, in which, in 2015 and 2016, refugees were welcomed in ways not played out in other European countries (see European Commis-

\footnotetext{
${ }^{3}$ HEIs are numbered from $1-3$ in each country. The labelling is consistent across all outputs from the wider project.
} 
sion/EACEA/Eurydice 2019 for a discussion of the impact of this on the German higher education sector). In Ireland, in contrast, differences by age were discussed much more frequently, with staff outlining some of the particular challenges of being a mature student, but also how such students were often the most motivated and eager to learn. Here, again, we can see echoes of dominant policy positions. In Ireland, policymakers have been keen to emphasise the importance of opening up the higher education system to a greater number of mature students, including those in fulltime work (Brooks 2018b). The narratives of the staff in UK-English institutions were distinct because of the prominence many gave to international students (i.e. those from outside the European Union) - reflective of the larger population of such students in UK-England than in the other five countries, but perhaps also the policy and media context in which such students are discussed regularly in terms of their economic benefit to the nation but also sometimes problematised as 'backdoor migrants' (Lomer 2017; Tannock 2018).

Social class was a rather more common theme across the various nations, discussed in some depth in Denmark, UK-England, Germany and Spain. However, the ways in which this was talked about differed somewhat. In Germany, for example, emphasis was placed more on the academic support and preparation that families with a history of higher education could offer their children, which 'first generation' students missed out on. In the other nations, however, material factors were more commonly foregrounded, including the impact of having to work during a degree programme (in UK-England and Spain), and the middle-class nature of many higher education institutions problematised:

We see that people from more humble origins have more difficulties in ... economic terms, in terms of like buying books or spending money for photocopies. One very important thing ... these people have to work [in paid work] more ... and then you have less time to study, much more stress and things like that. (Staff member, Spanish HEI 3)

A common theme across almost all of the countries, however, was that while some staff appeared to be aware of the difficulties students from less privileged backgrounds faced, it was often difficult to take action as they were usually unaware of the class background of their students until specific problems had emerged.

Different from all five other countries, however, was Poland. Here, almost all staff interviewed believed that students' social characteristics had very little, if any, impact on their studies and stated that they had given little thought to such issues in the past. The following comments are typical:

[With respect to] social classes, to be honest, I can't say anything about it, in the sense that I don't ask people about it, and they do not share any information like that with me. (Staff member, Polish HEI 1)

I don't see any differences between students. (Staff member, Polish HEI 2)

I do not care whether the students are rich or poor. For me, there's no difference between them. ... I treat them as blank boards, to write something on the board. (Staff member, Polish HEI 3) 
The Polish staff explained this position with reference to the fact that higher education was funded by the state, tuition fees were not charged (for study in public institutions), and entry was open to all with the required grades. One respondent also argued that Poland remained a largely non-hierarchical country because of its Communist past. In these accounts, unlike those from most of the other nations in our sample, there was no recognition that attainment, itself, could be affected by social background, or that students could experience the same higher education institution or course in different ways depending on their background. This, to some extent, illustrates the confusion, often seen within higher education and other areas of public policy, between equality of opportunity and equality of outcome.

Alongside these national differences were some notable institutional variations. In three countries (UK-England, Germany and Ireland), social class was discussed at greater length in the most prestigious university in each of the countries than in the other institutions in the sample. For example

It's clear that the upper levels of society are more represented in the student body than the
lower elements of society .... But the reality is, in the lower social strata, the pressure to start
earning money is greater, so it means the luxury of being able to spend four years, you know,
further educating yourself, for some people that just simply is not seen as an opportunity,
they cannot do that. (Staff member, Irish HEI 3)

Here, the elite context appeared to have brought issues related to social background to the fore. Other variations were apparent in two institutions (one in Germany and one in Denmark) that had unusual profiles-either because of the specific subject mix they offered (vocational subjects with a strong emphasis on social change), or the particular pedagogy that was employed (which included a focus on reducing power differentials between staff and students). In both of these organisations, staff were much more aware of the potential impact of social characteristics on access to and experiences within higher education-including the ways in which various hidden curricula and institutional norms can work to exclude 'non-traditional' students:

The core academic codes are more or less upper middle-class codes that still prevail ... So what is judged out and in is still based on some sort of Scandinavian upper middle-class normativity. (Staff member, Danish HEI 3)

This sensitivity to the impact of the dominant culture of higher education was notably absent from many of the other interviews, including those in other institutions in Denmark and Germany.

\section{Student Perspectives}

When we turn to the data from the student focus groups, a rather different picture emerges. In general, students across all six countries in the research believed that a variety of different social characteristics operated together to have a significant influence on what it meant to be a student and spent considerably more time than the staff outlining the nature of this impact. The most commonly discussed social 
characteristic was social class or family background. This was mentioned in all six countries. The ways in which it was thought to influence the nature of being a student included the extra pressure put on those from low-income families who had to engage in paid work to finance their studies (mentioned particularly in Germany, Ireland, Poland and Spain), and the greater sense of 'belongingness' felt by those with family experience of higher education (a notable theme in Denmark, Germany and Ireland). The examples below are illustrative:

Participant 1: I know a lot of people who have to have a job in college, whereas they can't go, and that kind of means that they have to miss certain like lectures and stuff, and so they'll find it hard just to keep up with the content and then to do the work on top of that. So I think social class does play a factor like.

Participant 2: Yeah, definitely. (Focus group participants, Irish HEI 3)

... those from a lower social class will probably have the added difficulty of having to work, perhaps, in order to pay for their studies, so, for them, it's much more difficult to finish their degree. (Focus group participant, Spanish HEI 1)

Gender was the next most commonly discussed characteristic, deemed relevant in all countries with the exception of UK-England. In Germany, Ireland, Poland and Spain, focus group participants believed that gender had a significant impact on the courses students chose, and thus the dynamics of particular programmes of study, which could be dominated by either men or women. Some students also talked about the genderdifferentiated norms that operated at university. For example, Irish students believed that a strong 'lad culture' within higher education encouraged many male students to adopt what they saw as a 'toxic masculinity' that revolved around heavy drinking and partying. In Denmark and Poland, some students believed that men tended to be privileged within the classroom and could dominate discussions, making it harder for women students to participate. For example:

I feel like men are more appreciated at my school because they are a minority. So I kind of feel like sometimes that they are ... like they're a bit more privileged, like the professors seem to be more optimistic sometimes about their inputs. (Focus group participant, Danish HEI 2)

Participant 1: Some lecturers don't challenge female students and give them the lowest grades that allow them to pass the exam because they assume that most of them are not going to work as engineers, anyway.

Participant 2: It exists. Just last week I overheard a conversation while waiting for consultations and two professors were talking about one female student in that manner, that she is stupid and she has no chance to pass their exams. In most cases, they try to encourage women, but on the other, you can still experience this kind of male chauvinism. (Focus group participants, Polish HEI 3)

Other social characteristics such as age, ethnicity, status as a home or international student, and whether one was disabled or not, were discussed in detail but not necessarily in all institutions, in all countries. As with the staff perspectives outlined above, these patterns were sometimes seemingly related to the wider national context. For example, fee status (whether an individual was classified as a home or international student) was discussed in UK-England, Ireland and Denmark but not the other three 
countries. It is perhaps unsurprising that this was evident in UK-England (mirroring in some way the staff perspectives discussed above), because of the large number of international students in UK-English universities and the public profile of issues related to international students. Ireland has also witnessed a sharp increase in its international student population (45\% from 2013-2017) as a result of a substantial marketing effort, while the position of international students in Denmark was the focus of considerable political debate around the time of the data collection. ${ }^{4}$ In contrast, the number of international students in Poland is significantly smaller, which is likely to explain their absence from Polish focus group discussions.

In general, across all our focus groups, the differences by social characteristics, which participants identified, were typically related to the surrounding social context - the students believed, on the whole, the differences played out in higher education were reflective of those in wider society. Many spoke, for example, of how gendered assumptions about jobs and areas of study affected the course choices made by students, which then led to very gender-imbalanced cohorts and affected the prestige of particular degrees (with those viewed as 'feminine' typically seen as lower status than others), and how 'clustering' by different ethnic groups was played out in university spaces in the same way as in wider society. However, it was also the case that, in some respects, the higher education system and higher education institutions were thought to have exerted an independent influence on these differences. In Germany and Denmark, but notably not in the other four countries, some focus group participants viewed higher education as an important space where individuals from different backgrounds could come together, integrate, and be treated the same. They believed that it was often more tolerant and open than many other spaces in their nation-state:

That's the great thing about uni, I think. That people are accepted ideally for who they are and that distinctions aren't made and also, that uni is a place where things such as gender are questioned, and some realise: "Hey, there's a third gender." So, a few fundamental questions that make uni a very open and tolerant place in my view. (Focus group participant, German HEI 1)

More common, however, was a view that higher education could often work to exacerbate the inequalities that were evident in wider society. Participants claimed, for example, that the hierarchical structure of the sector (more pronounced in some countries than others), compounded differences by social class, tending to further advantage those from more affluent backgrounds, who were more likely than their peers to gain access to prestigious institutions. Furthermore, some participants also emphasised the role of higher education staff in exacerbating inequalities in the classroom. As noted above, some Danish and Polish students believed that a number of lecturers tended to favour male students in class discussions.

\footnotetext{
${ }^{4}$ In Denmark, steps have been taken over recent years to reduce the number of international students, because of concerns that too few were staying to work in the country after graduation, and thus not making a sufficient financial contribution to the country through tax (Myklebust 2018).
} 


\section{Discussion}

We noted at the start of this chapter that there is considerable diversity, at a national level, in the social characteristics that governments have chosen to prioritise (Weedon and Riddell 2015). A similar degree of national variation is evident in the staff perspectives we have outlined above. Typically, staff considered only a relatively small number of social characteristics to be influential, and those that they foregrounded often appeared to be closely linked to the national context within which they were working. This is perhaps indicative of how policy can come to frame the ways in which we see the world, as Bacchi (2000) has argued. Even when the same social characteristic was discussed, different aspects were emphasised-for example, while some respondents stressed the impact of material factors in relation to social class, others placed more emphasis on perceived degrees of 'social fit'. In contrast, the students we spoke to appeared to have a broader, more all-encompassing view of salient social characteristics, with many such variables being mentioned within each focus group. This disconnect is important, as it signals rather different perspectives on the part of students and those who teach them and, perhaps, a lack of awareness on the part of staff of the factors that many students believe affect learning and the higher education experience more generally. The most extreme example of this difference emerged in Poland: while students in the focus groups were able to identify various ways in which family background, gender and place of origin all had an impact on what it meant to be a student in Poland today, many staff appeared to believe that such factors were not relevant to classroom interactions and had little effect on how their students experienced university life. While our data do not offer any clear explanations for this obvious variance, it is possible that it relates to the enduring dominance of Communist narratives about equality, and perhaps also the relatively late entry of Poland into European Union debates about the importance of promoting social inclusion within higher education. Staff views differed not only by nation but, in some cases, by institution (and, to some extent, also by individual). Indeed, as we have shown above, awareness of the possible impact of social class or family background appeared to be strongest in three of the highest status universities in our sample, and two other institutions that had an atypical profile (either in their pedagogical approach or the profile of the subjects they offered).

In contrast to the staff, the students we spoke to appeared to have more similar views about the impact of social characteristics across all six of our countries. This was particularly notable with reference to social class and/or family background. As documented above, they were able to provide detailed and nuanced accounts of the ways in which such factors impacted on both access to higher education, and experiences once there. Here, there was a notable contrast with some of the staff interviewees, who-particularly in Poland and Ireland-did not discuss social class/family background as a significant variable (and also with the perspectives of policymakers, which we have discussed elsewhere (see Brooks 2019)). A similar degree of understanding was apparent with respect to gender: inequalities in this area were discussed widely across the focus groups, with participants showing sensitivity 
to the ways in which women could be disadvantaged within university classrooms, and the pressures on men to conform to particular types of masculinity, for example. The similarities of students' views across our six European countries contrast not only with the perspectives of staff, but also the national differences evident at the policy level (for example, in relation to which social characteristics are prioritised in data-collecting and monitoring exercises) discussed above (Weedon and Riddell 2015).

An additional theme that emerged from the staff interviews was the difficulty of making judgements about the social composition of the student body without relevant data being made available. This was articulated particularly in relation to social class or family background, which is often less visible than other markers, such as ethnicity, age or disability. Such concerns about the lack of information within institutions reflect those voiced at the European policy level and discussed in an earlier part of this chapter. While European policymakers have criticised nation-states for the quality of their data collection and monitoring - and the European Commission has itself been criticised for using only 'soft' methods of governance to incentivise such data gathering (Weedon and Riddell 2015) — we see how, in the staff narratives, such issues can have implications at the local level, too. Various respondents in our study claimed that it was difficult for them to take action to reduce social inequalities, or even be aware of what such inequalities looked like, as they typically did not have any data on the social characteristics of their students (we noted this above, explicitly, in relation to social class).

In explaining the various differences they described, staff and many students made reference to the wider social context in which they were located. In this way, higher education was seen as a microcosm of society. There were, nevertheless, some exceptions to this general pattern. As noted above, students in Germany and Denmark echoed some of the arguments made by Bennett et al. (2017) about the university offering a more open and tolerant space, where a difference could be encountered and responded to in more positive ways than commonly seen in society. It is not clear from our data why these views were expressed in Germany and Denmark but not the other four countries, particularly since German higher education has often been criticised for its lack of social diversity (e.g. Neugebauer 2015). Students in the other four countries did not share these views about the openness of higher education institutions in their country. Many did, however, hold that such institutions did not merely reflect wider societal inequalities; some believed actions by staff (such as privileging male voices within classrooms) could exacerbate inequalities, as could the structure of the sector as a whole. An example of the latter point was the way in which university hierarchies were held to magnify differences between social groups-because, as discussed previously, across Europe non-traditional students are more likely to be found at lower status institutions (Marginson 2016; Pérez Cañado 2015).

Various policy implications follow from the discussion above. To drive a more consistent and less nationally variable emphasis on social inclusion, it may be useful for policymakers to collect and analyse data on a much more systematic basis and make more use of the student's voice. As outlined above, the students in our sam- 
ple appeared to have a comprehensive view of the possible impact of various social characteristics on learning, and how these could be exacerbated by higher educationspecific factors. The commonalities of perspectives across the six European countries was striking, and a notable contrast to the national variation highlighted both amongst the staff we interviewed and, as discussed at the start of this chapter, at the level of policy. Involving students more fully in initiatives to promote social inclusion may thus constitute a useful future focus for European policy-making.

Acknowledgements We are very grateful to all the staff and students, across Europe, who kindly gave up their time to participate in this project. We would also like to thank the European Research Council for the award of a Consolidator Grant to Rachel Brooks, which funded this research (grant number 681018_EUROSTUDENTS).

\section{References}

Ahmed, S. (2007). The language of diversity. Ethnic and Racial Studies 30(2), 235-256.

Bacchi, C. (2000). Policy as discourse: What does it mean? Where does it get us? Discourse: Studies in the Cultural Politics of Education, 21(1), 45-57.

Bathmaker, A-M., Ingram, N., Abrahams, J., Hoare, A., Waller, R., \& Bradley, H. (2016). Social class, higher education and social mobility: the degree generation, London: Palgrave Macmillan.

Bennett, K., Cochrane, A., Mohan, G. and Neal, S. (2017). Negotiating the educational spaces of urban multiculture: skills, competences and college life. Urban Studies, 54(10), 2305-2321.

Boliver, V. (2013). How fair is access to more prestigious UK universities? British Journal of Sociology, 64(2), 344-364.

Brooks, R. (2018a). Higher education mobilities: a cross-national European comparison. Geoforum, 93, 87-96.

Brooks, R. (2018b). Understanding the higher education student in Europe: a comparative analysis', Compare: A Journal of Comparative and International Education, 48(4), 500-517.

Brooks, R. (2019). The construction of higher education students within national policy: a crossEuropean comparison. Compare: A Journal of Comparative and International Education (online advance access).

Bunn, M., Threadgold, S. \& Burke, P. J. (2019). Class in Australian higher education: the university as a site of social reproduction. Journal of Sociology (advance online access).

Deem, R. \& Morley, L. (2006). Diversity in the academy? Staff perceptions of equality policies in six contemporary higher education institutions. Policy Futures in Education, 4(2), 185-202.

European Commission/EACEA/Eurydice (2018a). The European Higher Education Area in 2018: Bologna Process Implementation Report, Luxembourg: Publication Office of the European Union.

European Commission/EACEA/Eurydice (2018b). Structural Indicators for Monitoring Education and Training Systems in Europe -2018, Eurydice Report, Luxembourg: Publication Office of the European Union.

European Commission/EACEA/Eurydice (2019). Integrating Asylum Seekers and Refugees into Higher Education in Europe: National Policies and Measures. Eurydice Report, Luxembourg: Publications Office of the European Union.

Eurydice (2014). Modernisation of Higher Education in Europe: Access, Retention and Employability, Brussels: Education, Audiovisual and Culture Executive Agency.

Klein, U. (2016, January). Gender equality and diversity politics in higher education: Conflicts, challenges and requirements for collaboration. In Women's Studies International Forum (Vol. 54, pp. 147-156). Pergamon. 
Lomer, S. (2017). Recruiting Students in Higher Education. Representations and Rationales in British Policy, Basingstoke: Palgrave.

Marginson, S. (2016). The worldwide trend to high participation higher education: dynamics of social stratification in inclusive systems. Higher Education, 72, 413-434.

Myklebust, J. (2018). Ministry orders cut in international student numbers, University World News Available online at: https://www.university/worldnews.com/post.php?story=2018082915291392 (Accessed 16/10/19)

Neugebauer, M. (2015). The introduction of bachelor degrees and the under-representation of students from low social origin in higher education in Germany: a pseudo-panel approach. European Sociological Review, 31(5), 591-602.

Pérez Cañado, M. (2015). Democratization in European higher education: the past, present and future of the Bologna Process. In P. Blessinger \& J. Anchan (Eds). Democratizing Higher Education. International Comparative Perspectives, (pp. 44-60). New York: Routledge.

Robertson, S. (2009). Europe, competitiveness and higher education: An evolving project. In R. Dale \& S. Robertson (Eds.), Globalisation and Europeanisation in Education, (pp. 65-83). Oxford: Symposium Books.

Tannock, S. (2018). Educational Equality and International Students. Justice Across Borders, London: Basingstoke.

Weedon, E. \& Riddell, S. (2015). Higher Education in Europe: Widening Participation. In M. Shah, A. Bennett \& E. Southgate (Eds.), Widening Higher Education Participation: A Global Perspective (pp. 49-62). Amsterdam: Elsevier.

Open Access This chapter is licensed under the terms of the Creative Commons Attribution 4.0 International License (http://creativecommons.org/licenses/by/4.0/), which permits use, sharing, adaptation, distribution and reproduction in any medium or format, as long as you give appropriate credit to the original author(s) and the source, provide a link to the Creative Commons license and indicate if changes were made.

The images or other third party material in this chapter are included in the chapter's Creative Commons license, unless indicated otherwise in a credit line to the material. If material is not included in the chapter's Creative Commons license and your intended use is not permitted by statutory regulation or exceeds the permitted use, you will need to obtain permission directly from the copyright holder.

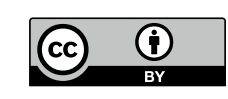

